\title{
Survey Burden for Family Members Surveyed About End-of-Life Care in the Intensive Care Unit
}

\author{
Erin K. Kross, MD, Elizabeth L. Nielsen, MPH, J. Randall Curtis, MD, MPH, and Ruth A. \\ Engelberg, PhD \\ Harborview Medical Center, Division of Pulmonary and Critical Care, Department of Medicine, \\ University of Washington, Seattle, Washington, USA
}

\begin{abstract}
Context-Family surveys are an important source of information about quality of end-of-life care in the intensive care unit (ICU). The burden associated with completing such surveys is not well studied.

Objectives-1) To assess the predictors of burden that families report with completing surveys for patients who died in the ICU; and 2) to examine associations between quality-of-care ratings and survey burden.

Methods-Data were collected from 14 hospitals as part of a cluster randomized trial to integrate palliative care into the ICU. Survey questions included: demographics, quality of dying, satisfaction with care, and overall level of burden associated with survey completion. Patient characteristics were identified from chart abstraction and death certificates. Multivariable linear regression with robust standard errors was used to examine associations between survey burden, subject characteristics, and family ratings of quality of care.
\end{abstract}

Results-Of the families surveyed, $62 \%$ rated the survey to be no or low burden. Family members of older patients reported less survey burden $(P=0.016)$ and those who lived with the patient reported higher survey burden $(P=0.043)$. Family members reporting lower ratings of satisfaction with care and quality of dying reported higher survey burden $(P<0.001)$.

Conclusion-The majority of families reported no to low burden. Family members who live with their loved one are particularly vulnerable to survey burden and those of older patients report less burden. The association between low quality of care ratings and survey burden suggests that the response bias in this type of research is towards overestimating quality of care,

(C) 2012 U.S. Cancer Pain Relief Committee. Published by Elsevier Inc. All rights reserved.

Address correspondence to: Erin K. Kross, MD, Division of Pulmonary and Critical Care, Box 359762, Harborview Medical Center, University of Washington, Seattle, WA 98104, USA, ekross@u.washington.edu.

Publisher's Disclaimer: This is a PDF file of an unedited manuscript that has been accepted for publication. As a service to our customers we are providing this early version of the manuscript. The manuscript will undergo copyediting, typesetting, and review of the resulting proof before it is published in its final citable form. Please note that during the production process errors may be discovered which could affect the content, and all legal disclaimers that apply to the journal pertain.

Disclosures

All of the authors report that no competing financial interests exist. Drs. Kross and Engelberg had full access to all the data in the study and take responsibility for the integrity of the data and the accuracy of the data analysis. All authors contributed to the study concept and design and critical review of the manuscript. Dr. Kross drafted the manuscript. Ms. Nielsen and Drs. Kross, Curtis, and Engelberg contributed to the statistical analysis and study supervision. Ms. Nielsen and Drs. Curtis and Engelberg contributed to data acquisition, analysis and interpretation, as well as the administrative, technical and material support. The study was registered at www.clinicaltrials.gov (NCT00685893). 


\section{Keywords}

Intensive care; end of life; family surveys; burden

\section{Introduction}

The intensive care unit (ICU) is a common place for end-of-life care in the U.S., with approximately one in five deaths occurring during or shortly after a stay in the ICU. ${ }^{1}$ Although there is an increasing emphasis on improving end-of-life care in the ICU, ${ }^{2}$ there are many challenges in assessing the dying experience and the quality of care for a patient in the ICU. Patient-assessed outcomes are not usually feasible, as less than 5\% of patients are able to communicate at the time that decisions are made to withdraw or withhold lifesustaining therapies. ${ }^{3}$ Instead, researchers have relied on surrogate assessments, including interviews and self-report surveys administered to family members that are designed to capture both the patient experience as well as the family's perceptions of their own experiences. ${ }^{4-7}$

Although these interviews and surveys have provided important outcome measures for studies of end-of-life care, ${ }^{2,8}$ there have been concerns that these assessments are burdensome, and may even be harmful to terminally ill patients and their caregivers. ${ }^{9-12}$ However, some recent studies suggest that neither patients nor family members find surveys distressing or difficult. ${ }^{9,13}$ In a recent in-person interview study with patients with an estimated six months or less to live and their caregivers ( $n=893$ ), almost $90 \%$ reported little or no stress, whereas less than $2 \%$ reported great stress. ${ }^{13}$

Despite these findings, self-report survey response rates for after-death surveys of family members are often low, with rates commonly less than $65 \% .{ }^{14-17}$ For any respondent, there are both costs and benefits associated with completing a survey. Participants are most likely to return a survey when these factors are balanced or the benefits outweigh the costs. ${ }^{18}$ Although some factors have been identified by patients that discourage the completion of surveys about end-of-life care (e.g., length of the survey, structure of the questionnaire, difficulty of discussing end-of-life issues), ${ }^{9}$ more research is needed to understand factors that result in low survey response rates.

Our study sought to address the following three research questions: 1) what is the level of burden associated with after-death surveys of family members after death of their loved one in the ICU? 2) are there patient- or family-level predictors of high levels of survey burden for family members? and 3) are family ratings of quality of end-of-life care associated with survey burden? These questions were addressed through quantitative surveys completed by family members after the death of a loved one in the ICU as well as through qualitative analyses of comments on these surveys.

\section{Methods}

\section{Design}

Data were collected as part of a cluster randomized trial in the Seattle-Tacoma, Washington area that was designed to evaluate the efficacy of a multifaceted, interdisciplinary intervention to improve palliative care in the ICU. ${ }^{15}, 19$ There were 16 hospitals in the Seattle-Tacoma area that had enough critically ill patients to be eligible and 15 agreed to participate in the study. Of the 15 participating hospitals, we collected family surveys and abstracted medical records for 14: two were pilot sites for the randomized trial, ${ }^{19}$ and 12 were included in the randomized trial. ${ }^{15}$ One of the hospitals that was a pilot site for study 
feasibility did not include chart abstraction and, therefore, is not included in this analysis. The 14 hospitals in this sample included two university-affiliated teaching hospitals, three community-based teaching hospitals, and nine community-based non-teaching hospitals. All study procedures were approved by the institutional review boards of all sites.

\section{Study Participants}

All patients who died in the ICU, after a minimum stay of six hours and within 30 hours of transfer from the ICU, were eligible. Patients were identified through hospital discharge and transfer logs.

\section{Data Collection}

Survey Methods-At one site, the patient's next of kin was identified from the electronic medical record; at other sites, surveys were mailed to patient homes and addressed, "To the family of [patient's name]." Surveys were written in English. Most surveys were mailed within one to two months after the patient's death (72\%), with a range from one to 29 months (80\% mailed less than six months after the patient's death). The survey packet included a cover letter explaining the study, a consent form, a $\$ 10$ incentive, a postage-paid return envelope, and the questionnaire booklet. The questionnaire booklet included demographic questions (13 items), the Quality of Dying and Death (QODD) questionnaire (23 items), ${ }^{20}$ the Family Satisfaction with the ICU (FS-ICU) survey (34 items), ${ }^{16,21}$ and a single question asking how much burden the respondent experienced completing the survey. The questionnaire took about 20 minutes to complete. Reminder or thank-you postcards were sent two weeks after the initial mailing. Second survey packets were sent after four weeks if there was no response to the initial mailing.

All surveys, both pre- and post-intervention, from the 12 hospitals participating in the randomized trial included the question about survey burden. The two pilot sites included the survey burden question only in those surveys that were sent in the post-intervention period, and so we have excluded participants from the pre-intervention period at the pilot sites. Survey mailings began in May 2004 and ended in May 2008.

Chart Abstraction-Chart abstraction was completed on all eligible patients. Data abstractors were trained as described previously. ${ }^{22}$ For ongoing quality control, a co-review of a $5 \%$ random sample of patients' charts was done, ensuring agreements of $\geq 95 \%$ on all of the 440 abstracted data elements.

Death Certificate Data-Washington State releases confidential electronic death certificate data linked by a patient identifier for the purposes of research. We used these records to provide data that were unavailable or incomplete in the medical record, including patient race/ethnicity, education, marital status and cause of death.

\section{Variables}

Outcome-Survey Burden-Our primary outcome was respondents' answers to the question, "Overall, how much of a burden on you was this questionnaire?" Respondents answered using a Likert scale that ranged from 0 "no burden at all" to 10 "great burden." In addition, we examined narrative data in the form of written comments that participants were invited to give about particular items or the survey in general. Participants were encouraged to write these comments next to the item about which they had a concern or in a space reserved at the end of the survey. 
Predictors: Patient and Family Characteristics-Patient characteristics were collected from medical records and death certificates and examined for associations with survey burden. From medical records, we determined patient age, sex, hospital and ICU lengths of stay. From death certificates, we ascertained race/ethnicity, education, marital status, and cause of death (trauma, cancer or other). Family characteristics were derived from the family questionnaires and included age, sex, race/ethnicity, length and type of relationship with the decedent, whether they lived with the decedent, and education. Time from death to survey mailing was calculated using chart abstraction data (date of death) and study administrative data (first survey mailing date).

Predictors: QODD and FS-ICU—The QODD measures family-assessed quality of dying, and has established reliability and validity. ${ }^{6,23,24}$ The QODD score is a summation of the ratings on each item (values range 0 to 10) divided by the number of items completed, and is recalibrated to range from $0-100$. Higher scores indicate higher quality of dying and death. In addition, we examined a single-item quality of dying rating that has been used previously. $^{25}$

The FS-ICU is a reliable and valid 34-item questionnaire measuring family satisfaction with ICU care. ${ }^{16,21,26}$ Scoring based on 24 items provided scores for total satisfaction, as well as two domain scores - satisfaction with care and satisfaction with decision making. ${ }^{27}$ The scoring involves recoding and recalibrating individual items to a $0-100$ range and averaging the available recalibrated items (requiring at least $70 \%$ valid); higher values indicate higher satisfaction. ${ }^{27}$

\section{Analyses}

To describe responses to the quantitative burden question, we used descriptive statistics to analyze the proportion of respondents who reported no burden (rating of 0 ), low burden (ratings 1 through 3), moderate burden (ratings 4 through 7) or great burden (ratings 8 through 10). To describe responses to the narrative, open-ended comments about survey burden, we used content analysis and categorized these responses. ${ }^{28-30}$ In order to assess reliability, we had an independent reviewer code 25 randomly selected comments and compared agreement between codes. The inter-rater agreement was $88 \%$.

In order to identify patient and family characteristics that were associated with survey burden, we used multivariable analyses regressing the continuously scored burden question (range 0-10) on selected predictors. We chose robust standard errors to accommodate the non-normal distribution of the burden question. In these regression models, we adjusted for hospital site using dummy variables as well as for intervention status. Initially, we examined each patient and family characteristic individually and bivariately with survey burden outcome. We then used multivariable analyses that included all patient and family characteristics that showed a trend toward association with survey burden $(P<0.10)$ in the bivariate analyses, and included hospital site and intervention status.

Finally, in order to examine whether there was an association between family members' ratings of care and survey burden, we used the same multivariable regression model identified above, with each of the five measures of quality of care tested as predictors in separate models: QODD total score, QOD single item, FS-ICU total score and FS-ICU domain scores for satisfaction with care (FS-Care) and satisfaction with decision making (FS-DM). 


\section{Results}

There were a total of 2544 eligible family subjects contacted from the 14 hospitals during the study period. Of these, 1107 had a family member respond to the survey, for a response rate of $43.5 \%$. A total of 1079 (97.5\%) of these respondents answered the question about survey burden, which forms the cohort for our study. There were no significant differences in patient or family characteristics between those who answered the survey burden question and those who did not.

The majority of both patients and their family member respondents were white (86\%) (Table 1.) Family members were more often female, younger than the deceased patient, and knew the decedent for a mean of 43 years. The majority of family members lived with the decedents and was either their spouse/partner or adult child. Less than a quarter of patients died as a result of trauma or cancer.

Ratings of survey burden varied among family members. Of the 1079 family members, 298 (27.6\%) said the questionnaire was "no burden at all," 375 (34.8\%) rated the questionnaire as low burden (Likert scale ratings 1-3), $315(29.2 \%)$ rated the questionnaire as a moderate burden (ratings 4-7) and 91 (8.4\%) rated the questionnaire as very burdensome (ratings 810). Figure 1 shows the distribution of these responses.

Family members' open-ended comments about survey burden were provided by 78 (7.2\%) respondents. Sixty of these comments came from the 988 respondents with low and moderate burden ratings (rating less than 8 ) representing $6.1 \%$ of low/moderate burden participants (60/988), and 18 of these comments came from the 91 families who rated burden as very high ( 8 or greater) representing $19.8 \%$ of high burden participants (18/91). Three content areas were identified: 1) emotional responses to the survey; 2) logistical issues of survey completion (e.g., timing of the survey, language or knowledge barriers); and 3) therapeutic qualities of completing the survey. Table 2 presents representative quotes in each category. For both low/moderate and high burden groups, almost half of all comments addressed the emotional aspects associated with completing the survey and a quarter addressed logistic issues surrounding survey completion. By contrast, comments were qualitatively different by burden-level group on the therapeutic value of survey completion; about a quarter of comments from respondents with low and moderate burden ratings mentioned therapeutic qualities associated with survey completion whereas only one respondent from the high burden rating group mentioned this aspect. Another qualitative difference between the two burden-level groups was that the comments of those with high burden appeared to demonstrate a higher degree of emotional distress associated with survey completion (Table 2).

Regression results using single predictors, adjusted for hospital site and intervention status, identified two patient characteristics and two family characteristics associated with burden responses (Table 3 ). Family members of patients who were white $(\beta=-0.584, P=0.027)$ and who were older $(\beta=-0.023$ for each year, $P<0.001)$ reported less burden associated with completing the questionnaire. There were no associations between survey burden and any of the following patient characteristics: patient sex, marital status, education, cause of death, or length of stay. Family members who lived with their loved one prior to death reported higher survey burden $(\beta=0.742, P<0.001)$. Additionally, adult children reported less survey burden than spouses of the deceased $(\beta=-0.649, P=0.001)$. There were no associations between survey burden and any of the following family characteristics: family member's sex, race, age, education, or years they had known the patient. There was no association between survey burden and the time from death to the first survey mailing. 
In the multivariable model including hospital site, intervention status and all patient and family characteristics, patient age and living with the decedent were independently associated with family report of survey burden (Table 4.) Family members of older patients reported less survey burden $(\beta=-0.017$ for each year, $P=0.016$ ), whereas family members of those who lived with their loved one reported higher survey burden $(\beta=0.531, P=0.043)$.

Finally, we examined associations between family member's ratings of quality of care or quality of dying and death in the ICU and their report of survey burden adjusting for patient and family race, patient age, living with the patient, relationship, hospital site and intervention status (Table 5). Lower ratings of quality of dying and death were associated with higher survey burden $(P<0.001)$. Similarly, lower ratings of satisfaction with care, including the total FS-ICU score as well as the two domain scores (satisfaction with care and satisfaction with decision making), were associated with higher ratings of survey burden (all $P<0.001)$.

\section{Discussion}

This study provides a unique opportunity to examine whether and to what degree families experience a self-report survey of end-of-life care in the ICU as burdensome. Although survey burden varied, very few respondents rated the survey to be a great burden. High survey burden is one factor that may reduce response rates to after-death surveys of family members, and this type of research has been suggested to be too stressful for patients and family members. ${ }^{10-12}$ However, our study suggests that this type of research places a relatively low burden on most family participants. Only about $10 \%$ of the participants of this study reported very high burden associated with completion of the survey.

Family members of younger patients reported more survey burden, as did family members of those who lived with their loved one. Because death in younger people is generally less expected, family members may be less prepared and, therefore, find it harder to answer questions about the quality of dying and death. They also may be experiencing stronger feelings of loss and bereavement, making it especially hard to respond to the survey items. ${ }^{31}$ Our group has previously shown that family members of younger patients have more symptoms of post-traumatic stress disorder after death of their loved one. ${ }^{32}$ Additionally, other research has shown that the quality of dying and death is rated lower for younger patients by both family members and nurses. ${ }^{25,33,34}$ Similarly, family members who lived with their loved one may be more likely to have been primary caregivers and also may be more troubled by feelings of bereavement, loss and depression. ${ }^{35}$ Of note was our finding that, although being a spouse was significantly associated with higher burden in separate predictor analyses, it was not supported in the multivariable analyses. In part, this may be a result of the correlation between living with a patient and being a spouse. Nonetheless, our findings suggest that living with the patient is a stronger predictor of survey burden than spousal relationship. These risk factors for increased survey burden highlight the need to find ways to reduce burden for particular groups of respondents.

Family members who gave low ratings to the quality of care of their loved one in the ICU reported more survey burden. These ratings of poorer quality were independently associated with higher survey burden. This finding has important implications for the generalizability of this research. Specifically, if family members with low ratings of the quality of end-oflife care find surveys very burdensome, they may be less likely to complete these surveys. As a result, findings from survey-based, after-death research may be biased, overestimating the quality of end-of-life care. In a separate investigation of these data where we compared responders and non-responders, we found that patients who received higher quality of palliative care were more likely to have a family member respond to the survey. That 
finding provides additional support to our hypothesis that the response bias in end-of-life care research is toward overestimating the quality of care. ${ }^{36}$

Our study has a number of limitations. First, we were able to examine factors associated with burden only among family members who responded to the questionnaire. It is possible that the burden of receiving a survey among non-respondents would be associated with different factors and characteristics. Second, although our sample was drawn from a number of sites, our relatively high rate of non-respondents limits our ability to generalize our findings to non-responders. Third, we did not specifically ask about the portions of the survey that were particularly burdensome and information about the burden of specific aspects of survey completion would be useful. However, we did obtain some information about burdensome aspects from the participants who provided narrative comments. Fourth, our surveys were not all mailed in the same time after death. Although the majority of surveys were mailed within the first two months after the patient's death, there was a range of time for initial mailing contact. However, we did not find any association between survey burden and the number of days from death to survey mailing. Prior research has shown no difference in self-reported distress among caregivers of hospice patients when surveyed at two weeks versus six weeks after the patient's death, supporting this finding. ${ }^{14}$ Finally, this study was conducted in one region of the United States and this may limit generalizability to other regions.

Assessments of the quality of palliative and end-of-life care often rely on surveys of patients' family members and the burden of these surveys is an important consideration. Our study suggests that for most family members who respond to such surveys, the burden is low. Family members of younger patients and those family members who live with the patient are at higher risk of experiencing survey burden. Our data suggest that improving quality of end-of-life care may reduce survey burden. In addition, attention to the survey length and ease of completion of the specific items also seems warranted. Future studies should examine ways to reduce survey burden associated with such surveys in order to enhance family experiences and also to improve response rates and reduce bias in outcome assessments.

\section{Acknowledgments}

This work was supported by the National Institute of Nursing Research (R01NR05226).

\section{References}

1. Angus DC, Barnato AE, Linde-Zwirble WT, et al. Use of intensive care at the end of life in the United States: an epidemiologic study. Crit Care Med. 2004; 32:638-643. [PubMed: 15090940]

2. Troung RD, Campbell ML, Curtis JR. Recommendations for end-of-life care in the intensive care unit: a consensus statement by the American College of Critical Care Medicine. Crit Care Med. 2008; 46:953-963.

3. Prendergast TJ, Luce JM. Increasing incidence of withholding and withdrawal of life support from the critically ill. Am J Respir Crit Care Med. 1997; 155:15-20. [PubMed: 9001282]

4. Addington-Hall J, McPherson C. After-death interviews with surrogates/bereaved family members: some issues of validity. J Pain Symptom Manage. 2001; 22:784-790. [PubMed: 11532591]

5. Curtis JR, Engelberg RA. Measuring success of interventions to improve the quality of end-of-life care in the intensive care unit. Crit Care Med. 2006; 34:S380-S387. [PubMed: 17057602]

6. Levy CR, Ely EW, Payne K, et al. Quality of dying and death in two medical ICUs: perceptions of family and clinicians. Chest. 2005; 127:1775-1783. [PubMed: 15888858]

7. Steinhauser KE, Clipp EC, Tulsky JA. Evolution in measuring the quality of dying. J Palliat Med. 2002; 5:407-414. [PubMed: 12133245] 
8. Teno JM. Measuring end-of-life care outcomes retrospectively. J Palliat Med. 2005; 8:S42-S49. [PubMed: 16499468]

9. Pessin H, Galietta M, Nelson CJ, et al. Burden and benefit of psychosocial research at the end of life. J Palliat Med. 2008; 11:627-632. [PubMed: 18454616]

10. Casarett DJ, Karlawish JH. Are special ethical guidelines needed for palliative care research? J Pain Symptom Manage. 2000; 20:130-139. [PubMed: 10989251]

11. Field, MJ.; Cassel, CK. Approaching death: Improving care at the end of life. Washington, DC: National Academy Press; 1997.

12. Koenig BA, Back AL, Crawley LM. Qualitative methods in end-of-life research: Recommendations to enhance the protection of human subjects. J Pain Symptom Manage. 2003; 25:S43-S52. [PubMed: 12691696]

13. Emanuel EJ, Fairclough DL, Wolfe P, Emanuel LL. Talking with terminally ill patients and their caregivers about death, dying, and bereavement: Is it stressful? Is it helpful? Arch Intern Med. 2004; 164:1999-2004. [PubMed: 15477434]

14. Casarett DJ, Crowley R, Hirschman KB. Surveys to assess satisfaction with end-of-life care. Does timing matter? J Pain Symptom Manage. 2003; 25:128-132. [PubMed: 12590028]

15. Curtis JR, Nielsen EL, Treece PD, et al. Effect of a quality-improvement intervention on end-oflife care in the intensive care unit: a randomized trial. Am J Respir Crit Care Med. 2011; 183(3): 348-355. [PubMed: 20833820]

16. Heyland DK, Rocker GM, Dodek PM, et al. Family satisfaction with care in the intensive care unit: results of a multiple center study. Crit Care Med. 2002; 30:1413-1418. [PubMed: 12130954]

17. Heyland DK, Rocker GM, O'Callaghan CJ, Dodek PM, Cook DJ. Dying in the ICU: perspectives of family members. Chest. 2003; 124:392-397. [PubMed: 12853551]

18. Dillman, DA. Mail and internet surveys: The tailored design method. New York: John Wiley \& Sons, Inc.; 2000.

19. Curtis JR, Treece PD, Nielsen EL, et al. Integrating palliative and critical care: evaluation of a quality-improvement intervention. Am J Respir Crit Care Med. 2008; 178:269-275. [PubMed: 18480429]

20. Patrick DL, Engelberg RA, Curtis JR. Evaluating the quality of dying and death. J Pain Symptom Manage. 2001; 22:717-726. [PubMed: 11532585]

21. Heyland DK, Tramer JE. Measuring family satisfaction with care in the intensive care unit: the development of a questionnaire and preliminary results. J Crit Care. 2001; 16:142-149. [PubMed: 11815899]

22. Gerstel E, Engleberg RA, Koepsell T, Curtis JR. Duration of withdrawal of life support in the intensive care unit and association with family satisfaction. Am J Respir Crit Care Med. 2008; 178:798-804. [PubMed: 18703787]

23. Curtis JR, Patrick DL, Engelberg RA, et al. A measure of the quality of dying and death: Initial validation using after-death interviews with family members. J Pain Symptom Manage. 2002; 24:17-31. [PubMed: 12183092]

24. Mularski RA, Curtis JR, Osborne ML, Engelberg RA, Ganzini L. Agreement among family members in their assessment of the quality of dying and death. J Pain Symptom Manage. 2004; 28:306-315. [PubMed: 15471648]

25. Glavan BJ, Engelberg RA, Downey L, Curtis JR. Using the medical record to evaluate the quality of end-of-life care in the intensive care unit. Crit Care Med. 2008; 36:1139-1146.

26. Wall RJ, Curtis JR, Cooke CR, Engelberg RA. Family satisfaction in the ICU: differences between families of survivors and nonsurvivors. Chest. 2007; 132:1425-1433. [PubMed: 17573519]

27. Wall RJ, Engelberg RA, Downey L, Heyland DK, Curtis JR. Refinement, scoring, and validation of the Family Satisfaction in the Intensive Care Unit (FS-ICU) survey. Crit Care Med. 2007; 35:271-279. [PubMed: 17133189]

28. Hsieh HF, Shannon SE. Three approaches to qualitative content analysis. Qual Health Res. 2005; 15:1277-1288. [PubMed: 16204405]

29. Cavanagh S. Content analysis: concepts, methods and applications. Nurse Researcher. 1997; 4:516. 
30. Weber, RP. Basic content analysis. Beverly Hills, CA: Sage; 1990.

31. Wright AA, Zhang B, Ray A, et al. Associations between end-of-life discussion, patient mental health, medical care near death, and caregiver bereavement adjustment. JAMA. 2008; 300:16651673. [PubMed: 18840840]

32. Kross EK, Engelberg RA, Gries CJ, et al. ICU care associated with symptoms of depression and PTSD among family members of those who die in the ICU. Chest. 2011; 139(4):795-801. [PubMed: 20829335]

33. Ganzini L, Goy ER, Miller LL, et al. Nurses' experiences with hospice patients who refuse food and fluids to hasten death. N Engl J Med. 2003; 349:359-365. [PubMed: 12878744]

34. Miyashita M, Morita T, Sato K, et al. Factors contributing to evaluation of a good death from the bereaved family member's perspective. Psychooncology. 2008; 17:612-620. [PubMed: 17992703]

35. Kiely DK, Prigerson H, Mitchell SL. Health care proxy grief symptoms before the death of nursing home residents with advanced dementia. Am J Geriatr Psychiatry. 2008; 16:664-673. [PubMed: 18669945]

36. Kross EK, Engelberg RA, Shannon SE, Curtis JR. Potential for response bias in family surveys about end of life care in the ICU. Chest. 2009; 136:1496-1502. [PubMed: 19617402] 


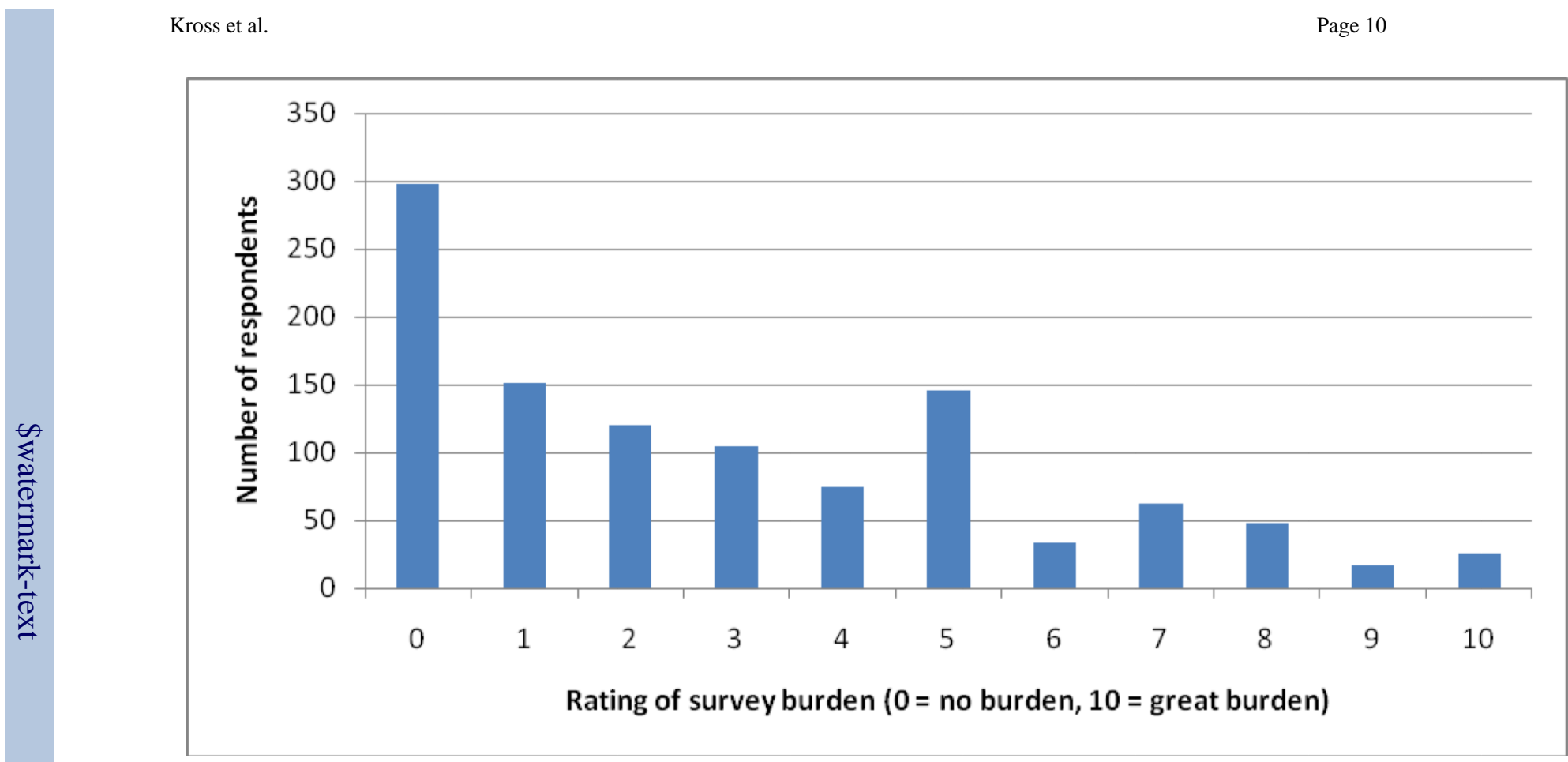

Figure 1.

Distribution of ratings of survey burden by 1079 family members completing a survey of end-of-life care in the ICU 
Table 1

Patient and Family Member Characteristics

\begin{tabular}{|c|c|c|}
\hline Demographics & $\begin{array}{l}\text { Patients } \\
(n=1079)\end{array}$ & $\begin{array}{l}\text { Family Members } \\
(n=1079)\end{array}$ \\
\hline Male, $n(\%)^{a}$ & $627(58.1)$ & $330(31.1)$ \\
\hline White, $n(\%) b$ & $934(86.6)$ & $907(86.2)$ \\
\hline Age in years, mean (SD) ${ }^{c}$ & $71.0(14.4)$ & $58.5(14.6)$ \\
\hline \multicolumn{3}{|l|}{ Education $^{d}$} \\
\hline$<8^{\text {th }}$ grade & $73(6.8)$ & $12(1.1)$ \\
\hline Some high school & $82(7.6)$ & $30(2.8)$ \\
\hline High school/GED & $397(36.8)$ & $180(16.7)$ \\
\hline Some college & $276(25.6)$ & $452(41.9)$ \\
\hline College degree & $173(16.0)$ & $207(19.2)$ \\
\hline Graduate/professional school & $67(6.2)$ & $174(16.1)$ \\
\hline Married, $n(\%)^{e}$ & $617(57.2)$ & \\
\hline \multicolumn{3}{|l|}{ Cause of death } \\
\hline Trauma & $91(8.4)$ & \\
\hline Cancer & $172(15.9)$ & \\
\hline Other & $816(75.6)$ & \\
\hline ICU length of stay in days, med (IQR) & $3(1,7)$ & \\
\hline Hospital length of stay in days, med (IQR) & $4(2,10)$ & \\
\hline Years known patient, mean (SD) $f$ & & $43.1(16.2)$ \\
\hline Lived with loved one, $n(\%) g$ & & $631(60.0)$ \\
\hline \multicolumn{3}{|l|}{ Relationship to decedent ${ }^{h}$} \\
\hline Spouse/partner & & $485(44.9)$ \\
\hline Child & & $385(35.7)$ \\
\hline \multicolumn{3}{|l|}{ Other } \\
\hline Sibling & & $62(5.7)$ \\
\hline Parent & & $43(4.0)$ \\
\hline Other relative & & $70(6.5)$ \\
\hline Friend & & $21(1.9)$ \\
\hline Days from death to first survey mailing, med (IQR) & & $36(31,76.5)$ \\
\hline
\end{tabular}

${ }^{a} 17$ missing for family members.

$b_{27 \text { missing for family members. }}$

$c_{18}$ missing for family members.

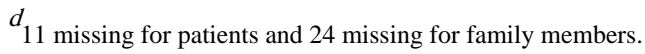

$e_{6 \text { missing. }}$ 
$f_{10 \text { missing. }}$

$g_{21 \text { missing. }}$

$h_{13 \text { missing. }}$ 
Table 2

Examples of Family Members' Narrative Comments, Grouped by Survey Burden Ratings

\begin{tabular}{|l|l|l|}
\hline & $\begin{array}{l}\text { Less Than Very Burdensome } \\
\text { (ratings 0-7) } \\
\mathbf{n = 6 0}\end{array}$ & $\begin{array}{l}\text { Very Burdensome } \\
\text { (ratings 8-10) } \\
\mathbf{n = 1 8}\end{array}$ \\
\hline $\begin{array}{l}\text { Emotional responses } \\
\text { to the survey }\end{array}$ & $\begin{array}{l}\text { "Just brought back some unpleasant memories and some good } \\
\text { ones." } \\
\text { "Not too much of a burden, just got me thinking about some } \\
\text { very painful, sad memories." } \\
\text { "Brought back a lot of unhappy memories of his last hours." }\end{array}$ & $\begin{array}{l}\text { "I cried every time I tried to complete this } \\
\text { questionnaire." } \\
\text { "It's difficult to relive those days." }\end{array}$ \\
\hline $\begin{array}{l}\text { Logistical issues } \\
\text { with survey } \\
\text { completion }\end{array}$ & $\begin{array}{l}\text { "Was not sure how to properly assess numbers on your scales." } \\
\text { "Just before the holidays was not a good time to receive this." }\end{array}$ & $\begin{array}{l}\text { "Because English is my second language." } \\
\text { "Too soon after my dad's passing." } \\
\text { "Because I didn't know enough to be really helpful." } \\
\text { appreciated." }\end{array}$ \\
\hline $\begin{array}{l}\text { Therapeunaire would have been better and } \\
\text { personal value from } \\
\text { completion of the } \\
\text { survey }\end{array}$ & $\begin{array}{l}\text { "Thank you for the chance to let out all my feedback on } \\
\text { mourning/losing a loved one." } \\
\text { "Actually helpful with the grief process." }\end{array}$ & $\begin{array}{l}\text { "I applaud your undertaking this survey - to gather } \\
\text { data and going beyond anecdotal information. } \\
\text { Thank you." }\end{array}$ \\
\hline
\end{tabular}




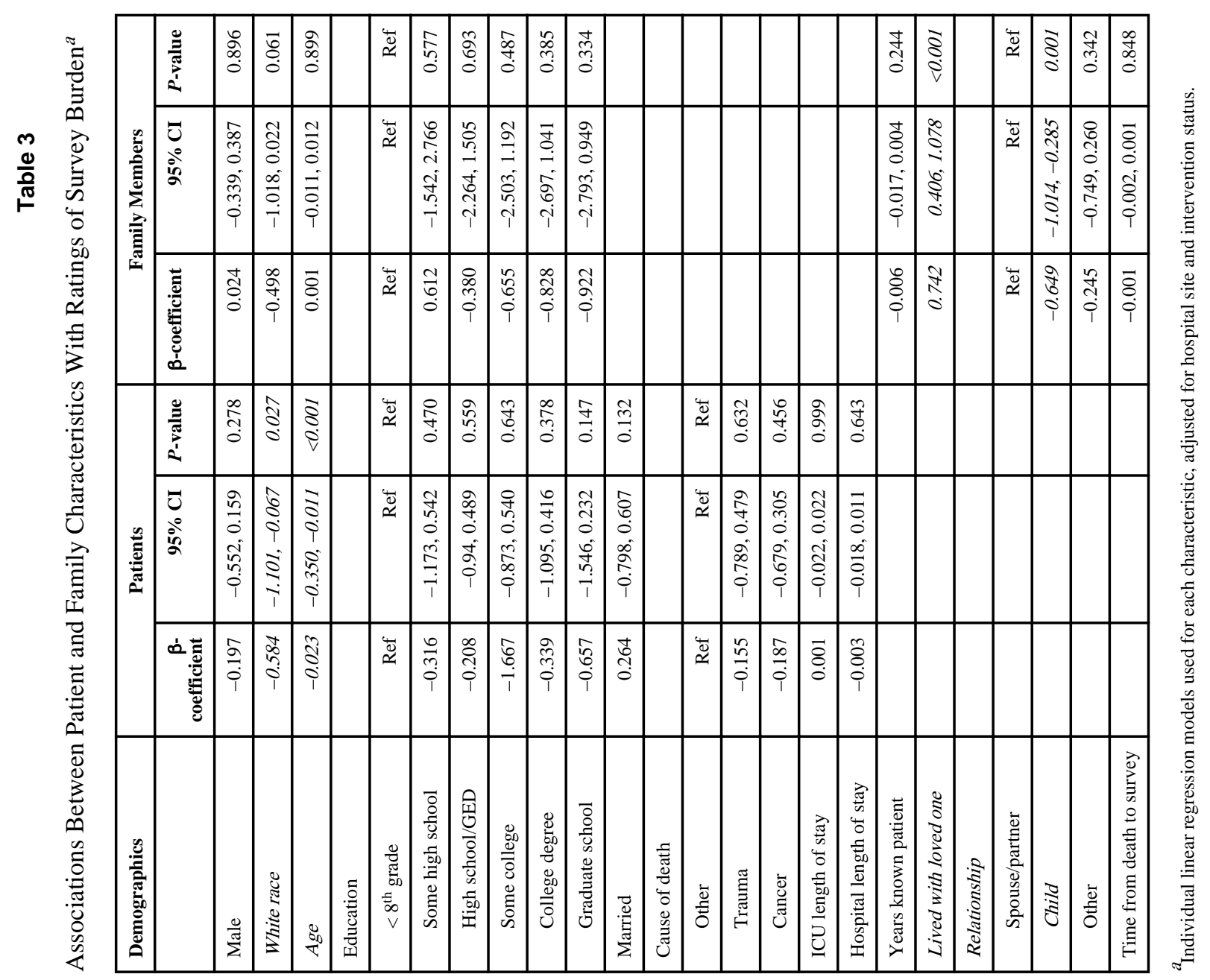


Table 4

Multivariable Associations Between Patient and Family Characteristics With Ratings of Survey Burden ${ }^{a}$

\begin{tabular}{|l|r|r|r|}
\hline Patient Demographics $(\boldsymbol{n = 1 0 7 9})$ & $\boldsymbol{\beta}$-coefficient & $\mathbf{9 5 \%} \mathbf{C I}$ & $\boldsymbol{P}$-value \\
\hline White race & -0.157 & $-0.979,0.664$ & 0.707 \\
\hline Age & -0.017 & $-0.031,-0.003$ & 0.016 \\
\hline Respondent's Demographics $(\boldsymbol{n = 1 0 7 9 )}$ & & & \\
\hline White race & -0.265 & $-1.093,0.564$ & 0.530 \\
\hline Lived with loved one & 0.531 & $0.017,1.045$ & 0.043 \\
\hline Relationship to decedent & & & \\
\hline Spouse/partner & Ref & & Ref \\
\hline Child & -0.186 & $-0.744,0.774$ & 0.513 \\
\hline Other & -0.021 & $0.017,0.618$ & 0.948 \\
\hline
\end{tabular}

${ }^{a}$ Multivariable regression model including all patient and family characteristics with bivariate associations of $P<0.10$, hospital site and intervention status. 
Table 5

Associations Between Quality of Care Ratings by Family Members and Family Members’ Ratings of Survey Burden $^{a}$

\begin{tabular}{|l|r|r|r|}
\hline Quality of Care Measure & $\beta$-coefficient & 95\% CI & $P$-value \\
\hline Quality of dying and death total score & -0.257 & $-0.334,-0.179$ & $<0.001$ \\
\hline Rating of quality of dying and death (single item) & -0.196 & $-0.257,-0.135$ & $<0.001$ \\
\hline Satisfaction with care in the ICU & -0.032 & $-0.041,-0.023$ & $<0.001$ \\
\hline Satisfaction with decision-making in the ICU & -0.030 & $-0.039,0.021$ & $<0.001$ \\
\hline Satisfaction with all aspects of care in the ICU & -0.028 & $-0.037,-0.020$ & $<0.001$ \\
\hline
\end{tabular}

andividual linear regression models for each outcome, adjusting for patient and family race, patient age, living with decedent, relationship, hospital site and intervention status. 